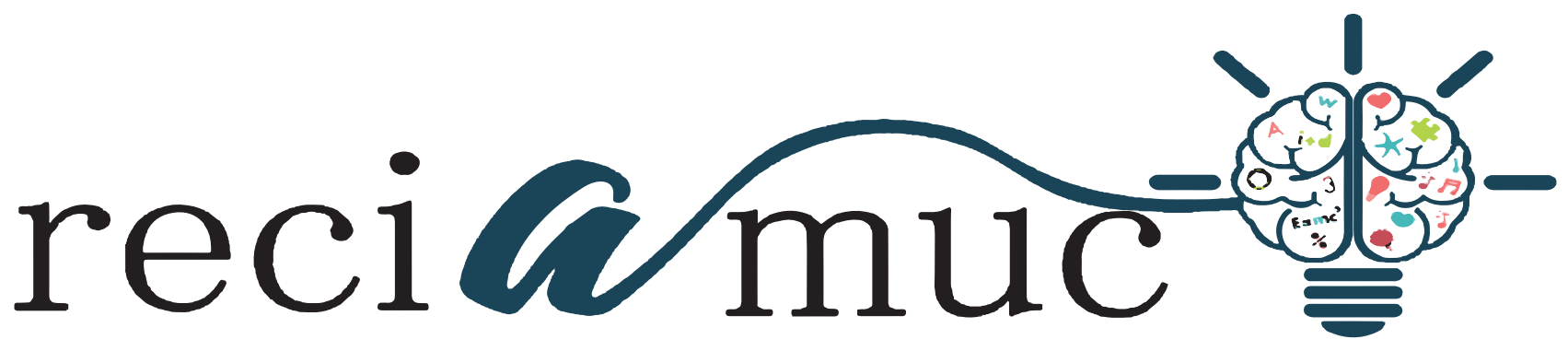

DOI: 10.26820/reciamuc/5.(4).noviembre.2021.154-162

URL: https://reciamuc.com/index.php/RECIAMUC/article/view/738

EDITORIAL: Saberes del Conocimiento

REVISTA: RECIAMUC

ISSN: 2588-0748

TIPO DE INVESTIGACIÓN: Artículo de Revisión

CÓDIGO UNESCO: 3213.13 Estomatología

PAGINAS: $154-162$

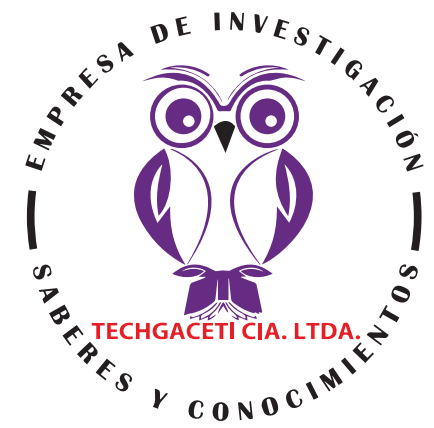

\title{
Recomendaciones para la atención odontológica segura durante la pandemia por Sars-CoV-2
}

Recommendations for safe dental care during the Sars-CoV-2 pandemic Recomendações para atendimento odontológico seguro durante a pandemia de Sars-CoV-2

\section{Sandra Sandoval Pedauga'; Miguel Carrasco Sierra2; Juan Manuel Sierra Zambrano ${ }^{3}$}

\section{RECIBIDO: 15/09/2021 ACEPTADO: 05/10/2021 PUBLICADO: 29/11/2021}

1. Especialista en Rehabilitación Oral; Odontóloga; Docente de la Universidad Laica "Eloy Alfaro" de Manabí, Manta, Ecuador; sandritasp@hotmail.com; iD https://orcid.org/0000-0002-6637-2902

2. Especialista de Primer Grado en Prótesis Estomatológica; Master en Atención de Urgencias en Estomatología; Doctor en Estomatología; Docente de la Universidad Laica "Eloy Alfaro" de Manabí, Manta, Ecuador; miguel. finca@yahoo.es; iD https://orcid.org/0000-0002-9336-4211

3. Especialista en Patología y Cirugía Bucal; Odontólogo; Docente de la Universidad Laica "Eloy Alfaro" de Manabí, Manta, Ecuador; e.jmsierra@gmail.com; iD https://orcid.org/0000-0002-9262-7382

\section{CORRESPONDENCIA \\ Sandra Sandoval Pedauga \\ sandritasp@hotmail.com \\ Guayaquil, Ecuador}

(c) RECIAMUC; Editorial Saberes del Conocimiento, 2021 


\section{RESUMEN}

La práctica odontológica es una de las ramas de la salud que está en riesgo constante de infección por COVID-19, por la exposición a secreciones salivales, es por ello que se han desarrollado las medidas y protocolos de bioseguridad para seguir prestando tan importante labor. La metodología utilizada para el presente trabajo de investigación, se enfoca hacia una metodología orientada hacia la necesidad de indagar en forma precisa y coherente una situación. Enmarcada dentro de una revisión bibliográfica de tipo documental, ya que nos vamos a ocupar de temas planteados a nivel teórico como es Recomendaciones para la atención odontológica segura durante la pandemia por Sars - CoV -2. La técnica para la recolección de datos está constituida por materiales impresos, audiovisuales y electrónicos, estos últimos como Google Académico, PubMed, entre otros. La información aquí obtenida será revisada para su posterior análisis. La práctica dental está en la segunda línea de combate y riesgos ante el contagio del COVID-19, a pesar de que, por la naturaleza de su trabajo, al tener que estar en contacto con secreciones salivales, pareciera ser un caldo de cultivo para la propagación del virus. Sin embargo, gracias a las guías prácticas desarrolladas por las organizaciones que rigen la materia en cuanto a la salud bucal, se definieron los protocolos de atención a personas con necesidades de atención en odontología. Y estos protocolos confirman a nivel internacional, que los contagios entre el personal de la salud bucal ha sido el más bajo que el resto del personal de salud. En una encuesta realizada a 2.200 dentistas en España, solo el 33,5\% se ha realizo una prueba PCR, solo el 4\% dio positivo y de ellos el 1,6\% se sospechó que el contagio fue en el ámbito laboral. Estos datos demuestran que el empleo de los protocolos de seguridad, bien llevados a cabo y de una manera estricta son eficaces. Hay una gama amplia de protocolos de seguridad para la atención de personas que necesitan ayuda odontológica, está dentro del personal, de las clínicas o consultorios dentales hacerlas cumplir para evitar la propagación del virus.

Palabras clave: Atención, Dental, Bioseguridad, Gel, Cubrebocas.

\section{ABSTRACT}

Dental practice is one of the branches of health that is at constant risk of infection by COVID-19, due to exposure to salivary secretions, which is why biosafety measures and protocols have been developed to continue providing such important work. The methodology used for this research work is focused on a methodology oriented towards the need to investigate a situation precisely and coherently. Framed within a bibliographic review of a documentary type, since we are going to deal with issues raised at a theoretical level such as Recommendations for safe dental care during the Sars - CoV -2 pandemic. The technique for data collection is made up of printed, audiovisual and electronic materials, the latter such as Google Scholar, PubMed, among others. The information obtained here will be reviewed for further analysis. The dental practice is in the second line of combat and risks in the face of the contagion of COVID-19, despite the fact that, due to the nature of its work, having to be in contact with salivary secretions, it seems to be a breeding ground for the spread of the virus. However, thanks to the practical guides developed by the organizations that govern the matter in terms of oral health, the care protocols for people with dental care needs were defined. And these protocols confirm at an international level that contagion among oral health personnel has been lower than that of other health personnel. In a survey of 2,200 dentists in Spain, only 33.5\% had a PCR test carried out, only $4 \%$ were positive and $1.6 \%$ of them suspected that the contagion was in the workplace. These data show that the use of security protocols, well carried out and in a strict manner, are effective. There is a wide range of safety protocols for the care of people who need dental help, it is within the staff, clinics or dental offices to enforce them to prevent the spread of the virus.

Keywords: Attention, Dental, Biosafety, Gel, Mouth Cover.

\section{RESUMO}

A prática odontológica é um dos ramos da saúde que está em constante risco de infecção pelo COVID-19, devido à exposição às secreções salivares, motivo pelo qual medidas e protocolos de biossegurança têm sido desenvolvidos para dar continuidade a um trabalho tão importante. A metodologia utilizada para este trabalho de investigação centra-se numa metodologia orientada para a necessidade de investigar uma situação de forma precisa e coerente. Enquadrado dentro de uma revisão bibliográfica de tipo documental, uma vez que trataremos de questões levantadas em um nível teórico como Recomendações para atendimento odontológico seguro durante a pandemia Sars - CoV -2. A técnica de coleta de dados é composta por materiais impressos, audiovisuais e eletrônicos, estes últimos como Google Scholar, PubMed, entre outros. As informações aqui obtidas serão revisadas para análises posteriores. O consultório odontológico encontra-se na segunda linha de combate e arrisca-se ao contágio da COVID-19, apesar de, pela natureza do seu trabalho, ter que estar em contato com secreções salivares, parece ser um terreno fértil para a propagação do vírus. No entanto, graças aos guias práticos desenvolvidos pelas entidades que regem o assunto em termos de saúde oral, foram definidos os protocolos de atendimento às pessoas com necessidades de cuidados dentais. E esses protocolos confirmam em nível internacional que o contágio entre profissionais de saúde bucal tem sido menor do que entre outros profissionais de saúde. Em uma pesquisa com 2.200 dentistas na Espanha, apenas $33,5 \%$ realizaram o teste de PCR, apenas $4 \%$ deram positivo e 1,6\% deles suspeitou que o contágio foi no local de trabalho. Esses dados mostram que a utilização de protocolos de segurança, bem executados e de forma rígida, são eficazes. Existe uma ampla gama de protocolos de segurança para o atendimento de pessoas que precisam de ajuda odontológica, seja dentro da equipe, clínicas ou consultórios odontológicos para aplicá-los para prevenir a propagação do vírus.

Palavras-chave: Atenção, Odontológico, Biossegurança, Gel, Protetor Bucal. 


\section{Introducción}

La COVID-19 (SARS-CoV 2), nos ha llevado a un nuevo estilo de vida, con diversos métodos de protección para evitar el contagio. El campo odontológico es uno de los más expuestos, ya que el principal método de transmisión es a través de la saliva. Por este motivo, los odontólogos han buscado nuevas modalidades de atención para evitar la propagación de dicho virus, las cuales se van actualizando constantemente (Perez-Muñante, Quintanilla-Ramos, \& Sihuay-Torres, 2021, pág. 107).

La atención dental implica una serie de características únicas que aumentan el riesgo de infección cruzada. Por esa razón, los odontólogos son los trabajadores de la salud más expuestos al riesgo de ser afectados por el COVID-19. Sumado a esto, las medidas de protección que comúnmente se tenían, ahora ya no son lo suficientemente efectivas para prevenir la propagación del COVID-19 (Vilca, 2020, pág. 60).

Los pacientes y profesionales dentales pueden estar expuestos a agentes patógenos microorganismos, incluidos virus y bacterias que infectan la boca cavidad y tracto respiratorio. Los entornos de cuidado dental invariablemente llevan al riesgo de infección de coronavirus COVID-19 debido a la especificidad de sus procedimientos, que implica la comunicación cara a cara con pacientes y exposición frecuente a saliva, sangre y a otros fluidos (Sepúlveda-Verdugo, Secchi-Álvarez, \& Donoso-Hofer, 2020, pág. 280).

La práctica odontológica es sin duda alguna un foco peligroso de posible transmisión debido al manejo directo de la saliva y de los aerosoles que se producen en los diversos procedimientos odontológicos, pero ¿Cuál es el papel del odontólogo ante esta enfermedad? Esto se responde 1) estableciendo las barreras de protección adecuadas, 2) delimitando los tratamientos de emergencia en pacientes vulnerables y 3) brindando la información adecuada al paciente (Suas-
te-Olmos, Cuevas-González, Calderón, \& González, 2020, pág. 102).

Con el reinicio de las actividades laborales y económicas y en un entorno llamado NUEVA NORMALIDAD, el odontólogo debe estar preparado para dar a los pacientes y al personal (clínico, administrativo, de laboratorio y otros) seguridad antiinfecciosa contra SARS-CoV-2. Acciones que deben ser adecuadamente comunicadas, entendidas y ejecutadas, ponderando el beneficio directo como familiar y hacia la sociedad (Suárez \& Guzmán, 2020, pág. 138).

Las recomendaciones para la atención de urgencia de especialidades odontológicas en fase IV COVID-19, considera asegurar acceso a las atenciones odontológicas catalogadas como críticas, es decir, cuadros clínicos que pueden agudizarse en el corto plazo (2 semanas) y los controles derivados de los cuadros clínicos antes mencionados. Dentro del área de ortodoncia, se sugiere previo a la atención del paciente, realizar un cuestionario que permita determinar si su diagnóstico coincide con el de una urgencia ortodóncica, definiéndose ésta como: un problema de salud oral que surge a raíz de un tratamiento ortodóncico, el cual necesita de una atención dental rápida para ser resuelto (Matus-Abásolo, Nemeth-Kohanszky, \& Inostroza-Tapia, 2020, pág. 490). 


\begin{tabular}{|c|c|c|c|c|}
\hline Pais & Tipo información & $\begin{array}{l}\text { Tamaño } \\
\text { muestral }\end{array}$ & Prevalencia & Fuente \\
\hline Estados Unidos & Encuesta a dentistas & 2195 & $0,9 \%$ (PCR) & Ret 33 \\
\hline Italia & $\begin{array}{l}\text { Estudio en clinicas dentales } \\
\text { públicas }\end{array}$ & ND & $0,9 \%$ (PCR) & Ref 34 \\
\hline Austria & Base de datos dentistas & ND & $1 \%(\mathrm{PCR})$ & Ret 35 \\
\hline Finlandia & Base de datos dentistas & ND & $\begin{array}{l}\text { No COVID-19 } \\
\text { detectado }\end{array}$ & Ref 35 \\
\hline Portugal & Encuesta a dentistas & ND & $0,5 \%$ (método?) & Ref 35 \\
\hline Paises Bajos & $\begin{array}{l}\text { Encuesta personal sanitario } \\
\text { (incluye dentistas) }\end{array}$ & ND & $0,9 \%$ (PCR) & Ret 36 \\
\hline China & $\begin{array}{l}\text { Hospital Dental Universitario } \\
\text { Wuhan }\end{array}$ & 1098 & $0.8 \%$ (PCR) & Ret 37 \\
\hline España & $\begin{array}{l}\text { Encuesta a dentistas (mayo } \\
\text { 2020) }\end{array}$ & 1738 & $\begin{array}{l}1,4 \% \text { (PCR) } \\
1,6 \% \text { (test rápidos) }\end{array}$ & Ref 38 \\
\hline España & $\begin{array}{l}\text { Encuesta a dentistas } \\
\text { (septiembre 2020) }\end{array}$ & 2200 & $1,6 \%$ (PCR) & Ret 39 \\
\hline
\end{tabular}

Imagen 1. Resumen de estudios de prevalencia COVID-19 personal dental.

Fuente: (Dental, 2020).

Como se puede observar en la imagen 1. En 9 países se han realizado estudios de prevalencia de COVID-19 en el personal dental en el año 2020. Los resultados obtenidos indican que, de todos los odontólogos o dentistas de dichos países, su relación de contagio esta entre el 0,5 al $2 \%$, cifra muy baja con respecto al resto del personal de salud, que está dentro de la primera línea de batalla en contra de este virus, también habría que evaluar cuántos de estos porcentajes de contagios, se dieron dentro del entorno laboral ya que no se puede afirmar que todos los contagios fueron trabajando.

\section{Metodología}

La metodología utilizada para el presente trabajo de investigación, se enfoca hacia una metodología orientada hacia la necesidad de indagar en forma precisa y coherente una situación. Enmarcada dentro de una revisión bibliográfica de tipo documental, ya que nos vamos a ocupar de temas planteados a nivel teórico como es Recomendaciones para la atención odontológica segura durante la pandemia por Sars - Cov -2. La técnica para la recolección de datos está constituida por materiales impresos, audiovisuales y electrónicos, estos últimos como Google Académico, PubMed, entre otros. La información aquí obtenida será revisada para su posterior análisis.

\section{Resultados}

\section{Medidas preventivas en la práctica odon- tológica}

\section{Equipos de Protección Personal (EPP)}

Se sugiere el uso de una lista de verificación, la cual debe contener elementos obligatorios, tales como: batas impermeables descartables de largo completo (EPP intermedio), mamelucos (EPP Avanzado), respiradores N95, FFP2 o FFP3, careta completa o visera, guantes, y protectores oculares. De forma que se garantice la protección tanto de los pacientes como de los profesionales, para seguir correctamente un protocolo que permita evitar contagios o propagaciones dentro de la práctica odontológica (Camacho, y otros, 2021, pág. 203).

\section{Lavado e higienización las manos}

El lavado o higiene de manos (la disposición más importante para aminorar el peligro de transmisión del virus) con jabón y agua, o con una sustancia a base de alcohol, principalmente luego de entrar en contacto con sus secreciones; es una de las 
medidas más destacadas por la OMS y las autoridades sanitarias para limitar la propagación del coronavirus. Se ha sugerido que los cirujanos dentistas tiene que lavarse las manos antes de revisar a un paciente, previo a cualquier procedimiento dental, luego de atender al paciente y después de pulsar cualquier equipo y superficies circundantes sin desinfectar, tras contacto con la mucosa oral, heridas o piel dañada, sangre, fluidos corporales, saliva y excretas (Camacho, y otros, 2021, pág. 203).

3. Uso de enjuague bucal antes de la atención odontológica.

El virus SARS-CoV-2 puede permanecer en las superficies por horas, e incluso días. Es por ello que antes del examen intraoral, se recomienda el uso de un colutorio que contenga peróxido de hidrógeno al 1\% o Povidona yodada al 0,2\%, debido a que el síndrome respiratorio agudo severo-coronavirus-2 es muy susceptible a la oxidación, ello ayuda a la ya mencionada reducción de la carga viral en las gotitas y aerosoles (Camacho, y otros, 2021, pág. 203).

4. Uso de diques de goma para el aislamiento

Se ha demostrado que minimiza la producción de saliva y aerosoles contaminados con sangre, especialmente durante los procedimientos realizados con el uso de la turbina de las piezas de mano de alta velocidad e instrumentos ultrasónicos. La literatura indica que el uso de diques de caucho resultó en una disminución del $70 \%$ de partículas suspendidas en el aire dentro de aproximadamente tres pies de diámetro del campo operativo (Camacho, y otros, 2021, pág. 204).

\section{Recomendaciones en la sala de espera}

Los pacientes deben asistir con mascarilla y mantener distanciamiento social. La cantidad de pacientes en la sala de espera debe reducirse al mínimo, para eso es necesario espaciar las citas de atención. Además, los tiempos de espera y contacto deben ser cortos, es recomendable retirar todos los elementos no necesarios de la sala de espera (ej.; revistas) que puedan ser tocados, y que sean difícil de desinfectar. La sala de espera debe estar sala ventilada y con acceso a higiene de manos. Los pacientes deben realizar un lavado de manos con agua y jabón o con desinfectantes a base de alcohol, antes y después de la atención dental (Martínez-Camus \& Yévenes-Huaiquinao, 2020, pág. 290).

- Tapete humedecido. Se colocará en la entrada. Humedecido en una solución de hipoclorito de sodio al $1.5 \%$ para que las personas que ingresen se limpien los zapatos (Suárez \& Guzmán, 2020, pág. 139).

- Bloqueo o disminución de asientos. Se bloquearán asientos en la sala de espera o se separarán más de $1.5 \mathrm{~m}$ sillones o sillas individuales (sana distancia). Inclusive pudiera ser necesario reducir el número de asientos disponibles en la sala de espera (Suárez \& Guzmán, 2020, pág. 139).

- Visitas personales y acompañantes. No están permitidas las visitas personales. Es preferible que sólo llegue la persona que va a recibir atención. Los acompañantes no deben esperar dentro de las instalaciones clínicas. Se podrá contactar con ellos telefónicamente al final de la atención del paciente citado. Excepciones serán hechas con menores de edad y personas discapacitadas que requieran asistencia adicional (Suárez \& Guzmán, 2020, pág. 140).

- Interrogatorio. A todos los pacientes y acompañantes se les pedirá contestar un cuestionario con las siguientes preguntas. En los últimos 15 días: $\mathrm{A}$. ¿Ha tenido fiebre? B. ¿Ha tenido malestar general, dolor muscular o deterioro del estado físico? C. ¿Ha sufrido estornudos o tos? D. ¿Ha sufrido diarrea o trastornos digestivos? E. ¿Ha tenido pérdida 
del olfato o del gusto? F. ¿Ha tenido dificultad para respirar? G. ¿Ha estado en contacto con una persona positiva a COVID-19? H. ¿Ha sufrido COVID-19? Si alguna de las respuestas del listado de la $A$ a la G fuera positiva la cita deberá posponerse y referir al paciente a diagnóstico diferencial y eventual atención médica. Si la respuesta del ítem $\mathrm{H}(¿ \mathrm{Ha}$ sufrido COVID-19?) resultará positiva, la conducta a seguir será esclarecer si el paciente ya no es contagioso (Suárez \& Guzmán, 2020, pág. 141).

\section{Atención a pacientes recuperados}

No existe un consenso de cuándo un paciente que fue diagnosticado con la enfermedad puede interrumpir el aislamiento en el hogar. Algunos autores han indicado que el paciente debe ser considerado portador del virus hasta después de 30 días de confirmar su recuperación con una prueba de laboratorio. Otros indican que se debe esperar un tiempo de 7 días sin presentar sintomatología. Es necesario el juicio clínico para determinar la urgencia de la atención, y postergarla de ser posible (Martínez-Camus \& Yévenes-Huaiquinao, 2020, pág. 291).

7. Recomendaciones para la atención odontológica

- Prioritario: evaluar sintomatología de todo el personal involucrado y toma de temperatura $<37$ oC.

- Estado general de salud y viajes o contacto con alguien que haya viajado al extranjero en los últimos 14 días, aplica también para acompañantes de los pacientes.

- Temperatura < 37 oC.

- En áreas donde se haya expandido el virus, cualquier procedimiento de rutina deberá posponerse.

- Pacientes que hayan presentado la infección por COVID-19, se sugiere pos- poner los procedimientos hasta un mes después de aliviados los síntomas (Aguilera-Galaviz, Gaitán-Fonseca, \& Bermúdez-Jiménez, 2020, págs. 91-92).

- Acomodo del paciente en el sillón dental. Al introducir al paciente al operatorio se le pedirá nuevamente usar gel hidroalcohólico antibacterial o le será rociado material antiséptico en manos y antebrazos. Sus pertenencias deben haber sido almacenadas en lugares indicados, o provista por el área de recepción de una toalla desechable impregnada con antiséptico para que manipule las correas de bolso o mochila (Suárez \& Guzmán, 2020, pág. 142).

- Preparación de cara y boca. Dado el hecho de que el virus SARS-CoV-2 es susceptible a la peroxidación es recomendable que la asistente ofrezca al paciente una torunda o almohadilla de algodón empapada en una solución de peróxido de hidrógeno al 1.5\%, para que la persona se limpie la cara, haciéndolo del centro a la periferia. Posteriormente, se le dará un enjuague de Microdacyn 60 bucofaríngeo (ácido hipocloroso, cloro oxígeno, solución de superoxidación), o de yodopovidona al $0.2 \%$ o una solución de peróxido de hidrógeno al 1.5\% y se le pedirá que lo mantenga en la boca durante un minuto (Suárez \& Guzmán, 2020, pág. 142).

8. Evaluación bucal

- Enjuagues bucales preoperatorios (con contenido alcohólico o antisépticos orales) pueden reducir el número de microorganismos. Evitar enjuagues con hipoclorito de sodio (tóxico e irritante).

- Procedimientos que sean afines a provocar tos deberán evitarse (si es posible) o realizarlos cuidadosamente.

- Minimizar el uso de la jeringa triple en la medida de lo posible.

- Las radiografías intraorales pueden esti-

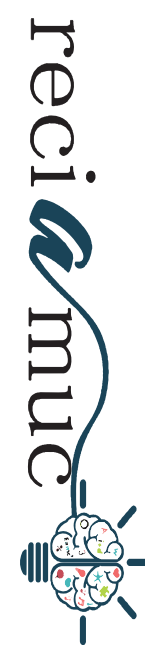




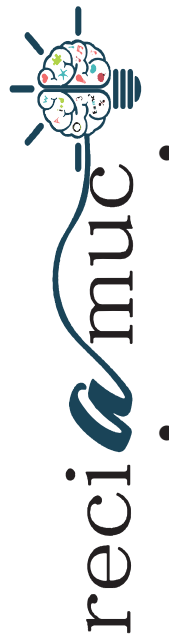

mular la secreción de saliva, tos o reflejo nauseoso.

- Se recomienda el uso de radiografías panorámicas o tomografía Cone Beam si es posible durante el brote del virus (Aguilera-Galaviz, Gaitán-Fonseca, \& Bermúdez-Jiménez, 2020, págs. 92-93).

- Suturas. En la realización de procedimientos quirúrgicos es preferible hacer uso de suturas absorbibles que no requieran el retiro de las mismas y así evitar citas que pudieran no ser necesarias (Suárez \& Guzmán, 2020, pág. 143).

- Sistema hidráulico. Aun cuando no hay soporte científico a la fecha que demuestre su eficacia contra el SARSCoV-2, puede recomendarse el uso de hipoclorito de sodio para limpiar y purgar instrumentos como pieza de mano, jeringa triple y eyectores (Suárez \& Guzmán, 2020, pág. 143).

- Fin de la cita. Una vez terminados los procedimientos odontológicos y el paciente haber sido despedido, el operador y su personal deberán lavarse manos y cara. Deberá limpiarse con guantes las superficies que hayan sido tocadas y se empleará un bactericida en aerosol para sanitizar el espacio del operatorio empleado (Suárez \& Guzmán, 2020, pág. 143).

- Desecho de la indumentaria de trabajo. Deberán retirarse guantes, cubrebocas, batas, todos los campos y material como gasas, algodón, carpules y colocarse en los botes de desechos contaminados. Éstos deberán tener tapa y pedal para abrirse con el pie. Lo mismo aplica para agujas, bisturíes y material quirúrgico desechable. Debe solicitarse a la compañía que se encarga de eliminar el material contaminado que aumente la frecuencia para su retiro de la clínica (Suárez \& Guzmán, 2020, págs. 143-144).

\section{Tratamiento de casos emergentes}

- Pulpitis reversible e irreversible.

- Absceso periapical agudo.

- Absceso periodontal.

- Periodontitis apical aguda.

- Celulitis.

- Trauma dental (excepto aquéllos que involucren esmalte o dentina sin la presencia de dolor).

- Pericoronitis.

- Sangrado oral.

- Sospecha de lesión patológica maligna.

- Fractura o pérdida de restauraciones asociada con dolor.

- Fractura o pérdida de prótesis fija o removible con la presencia de dolor o infección.

- Retiro de sutura asociada con procedimiento oral reciente (Aguilera-Galaviz, Gaitán-Fonseca, \& Bermúdez-Jiménez, 2020, pág. 93). 


\begin{tabular}{|c|c|c|c|}
\hline $\begin{array}{l}\text { Emergencias } \\
\text { Dentales }\end{array}$ & Urgencias Dentales & $\begin{array}{l}\text { Otros criterios de atención } \\
\text { de Urgencia Dental }\end{array}$ & $\begin{array}{l}\text { Tratamiento electivo } \\
\text { a postergar }\end{array}$ \\
\hline $\begin{array}{l}\text { Hemorragias/sangra } \\
\text { do profusos dificiles } \\
\text { de controlar } \\
\text { Infección y aumento } \\
\text { de volumen difuso } \\
\text { extra-intraoral, con } \\
\text { posible compromiso } \\
\text { de V.A } \\
\text { Trauma Maxilofacial } \\
\text { con posible } \\
\text { compromiso de V.A }\end{array}$ & $\begin{array}{l}\text { Pulpitis } \\
\text { Pericoronaritis } \\
\text { Complicacionespost- } \\
\text { exodoncia } \\
\text { Traumatismo Dertoalveolar } \\
\text { Infecciones odontogénicas } \\
\text { (localizadas) } \\
\text { Periodontitis/Gingivitis } \\
\text { Ulcerativa Necrotizante } \\
\text { Aguda } \\
\text { Biopsia de tejido anormal }\end{array}$ & $\begin{array}{l}\text { Remociones de suturas } \\
\text { Reparación y ajuste } \\
\text { protésioo en pacientes } \\
\text { oncológicos } \\
\text { Defocación en pacientes } \\
\text { oncológicos o con uso de } \\
\text { antiresortivos } \\
\text { Reparación protésica } \\
\text { /restauraciones cuando } \\
\text { función este comprometida } \\
\text { Ajuste ortodoncico cuando } \\
\text { aparatología genere } \\
\text { ulceraciones en mucosa }\end{array}$ & $\begin{array}{l}\text { Evaluaciones diagnosticas de } \\
\text { rutinas (incuye radiografias) } \\
\text { Controles clinicos-radiograficos } \\
\text { Tratamiento ortodoncico u otros } \\
\text { que no sean de manejo de dolor } \\
\text { infección trauma) } \\
\text { Exodoncias de dientes } \\
\text { asintomátcos } \\
\text { Tratamiento rehabilitador de } \\
\text { lesiones cariosas asintomáticas } \\
\text { Tratamiento estéticos } \\
\text { Tratamientos de rutinas } \\
\text { (blanqueamientos, destartrajes) }\end{array}$ \\
\hline
\end{tabular}

Imagen 2. Esquema de clasificación de atenciones. V.A: Vía Aérea. Aportes de Guía Minsal (GES) y American Dental Association (ADA). Sugerimos al tratante individualizar cada caso clínico.

Fuente: (Sepúlveda-Verdugo, Secchi-Álvarez, \& Donoso-Hofer, 2020)

\section{Conclusiones}

La práctica dental está en la segunda línea de combate y riesgos ante el contagio del COVID-19, a pesar de que, por la naturaleza de su trabajo, al tener que estar en contacto con secreciones salivales, pareciera ser un caldo de cultivo para la propagación del virus. Sin embargo, gracias a las guías prácticas desarrolladas por las organizaciones que rigen la materia en cuanto a la salud bucal, se definieron los protocolos de atención a personas con necesidades de atención en odontología. Y estos protocolos confirman a nivel internacional, que los contagios entre el personal de la salud bucal ha sido el más bajo que el resto del personal de salud. En una encuesta realizada a 2.200 dentistas en España, solo el 33,5\% se ha realizo una prueba PCR, solo el $4 \%$ dio positivo y de ellos el 1,6\% se sospechó que el contagio fue en el ámbito laboral. Estos datos demuestran que el empleo de los protocolos de seguridad, bien llevados a cabo y de una manera estricta son eficaces. Hay una gama amplia de protocolos de seguridad para la atención de personas que necesitan ayuda odontológica, está dentro del personal, de las clínicas o consultorios dentales hacerlas cumplir para evitar la propagación del virus.

\section{Bibliografía}

Aguilera-Galaviz, L., Gaitán-Fonseca, C., \& Bermúdez-Jiménez, C. (2020). Manejo del paciente en atención odontológica y bioseguridad del personal durante el brote de coronavirus SARSCoV-2 (COVID-19). Revista de la Asociación Dental Mexicana, 77(2), 88-95. doi:https://dx.doi. org/10.35366/93101

Camacho, Y. T., Benavides, V., Rivadeneira, K., Cárdenas, K., Ramírez, W., Heredia, E., \& Castañeda, M. (2021). COVID-19 y su impacto en la odontología. Revista Estomatológica Herediana, 31(3), 199207. doi:https://doi.org/10.20453/reh.v31i3.4050

Dental, G. (30 de 10 de 2020). Obtenido de https:// gacetadental.com/2020/10/dentistas-presentan-menos-contagios-covid-19-otros-profesionales-sanitarios-100674/

Martínez-Camus, D. C., \& Yévenes-Huaiquinao, S. (2020). Atención dental durante la pandemia COVID-19. International journal of odontostomatology, 14(3), 288-295. doi:http://dx.doi.org/10.4067/ S0718-381X2020000300288

Matus-Abásolo, C. P., Nemeth-Kohanszky, M., \& Inostroza-Tapia, M. (2020). Atención de Pacientes en Tratamiento de Ortodoncia Durante la Pandemia COVID-19 (SARS-CoV-2). Presentación de un Algoritmo. International journal of odontostomatology, 14(4), 489-494. doi:http://dx.doi.org/10.4067/ S0718-381X2020000400489

Perez-Muñante, K., Quintanilla-Ramos, G., \& Sihuay-Torres, K. (2021). Bioseguridad en la atención odontológica ante la pandemia COVID-19. Odontología sanmarquina, 24(1), 107-108. doi:h- 
ttps://doi.org/10.15381/os.v24i1.19704

Sepúlveda-Verdugo, C., Secchi-Álvarez, A., \& Donoso-Hofer, F. (2020). Consideraciones en la atención odontológica de urgencia en contexto de coronavirus COVID-19 (SARS-CoV-2). International journal of odontostomatology, 14(3), 279-284. doi:http:// dx.doi.org/10.4067/S0718-381X2020000300279

Suárez, J. L., \& Guzmán, L. (2020). Propuesta del modelo para control de infecciones en la consulta odontológica ante la pandemia de COVID-19. Revista de la Asociación Dental Mexicana, 77(3), 77(3), 137-145. doi:https://dx.doi. org/10.35366/94007
Suaste-Olmos, F., Cuevas-González, M., Calderón, A., \& González, J. (2020). Conociendo al COVID-19 y la labor odontológica ante la pandemia. Odontología sanmarquina, 23(2), 101-103. doi:https://doi.org/10.15381/os.v23i2.17753

Vilca, S. B. (2020). Recomendaciones para la atención odontológica durante la pandemia de COVID-19. Revista Odontológica Basadrina, 4(1), 5964. doi:https://doi.org/10.33326/26644649.2020.4. 1.917

\section{CITAR ESTE ARTICULO:}

Sandoval Pedauga, S., Carrasco Sierra, M., \& Sierra Zambrano, J. M. (2021). Recomendaciones para la atención odontológica segura durante la pandemia por Sars-CoV-2. RECIAMUC, 5(4), 154-162. https://doi.org/10.26820/reciamuc/5.(4).noviembre.2021.154-162

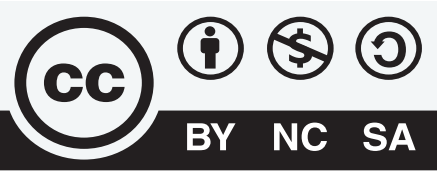

CREATIVE COMMONS RECONOCIMIENTO-NOCOMERCIAL-COMPARTIRIGUAL 4.0. 